\title{
A Review Exploring the Relationship Between Nursing Home Staffing and Antipsychotic Medication Use
}

\author{
T. Joseph Mattingly II
}

To view enhanced content go to www.neurologytherapy-open.com

Received: August 6, 2015 / Published online: September 2, 2015

(c) The Author(s) 2015. This article is published with open access at Springerlink.com

\section{ABSTRACT}

Staffing level requirements for nursing homes exist at state and federal levels in the United States. While quality of care measures may include antipsychotic (AP) prescribing, the appropriate use of APs as chemical restraints in nursing homes continues to be debated. Although the two variables appear to be related, improved research methods and availability of accurate staffing data will be needed to understand causal relationships regarding AP use for facility dwelling patients.

Keywords: Antipsychotics; Long-term care; Nursing home; Quality; Staffing

Electronic supplementary material The online version of this article (doi:10.1007/s40120-015-0032-2) contains supplementary material, which is available to authorized users.

T. J. Mattingly II ( $\square)$

Department of Pharmacy Practice and Science, University of Maryland School of Pharmacy, Baltimore, MD, USA

e-mail: jmattingly@rx.umaryland.edu

\section{INTRODUCTION}

Patients are admitted to nursing homes (NHs) to receive an increased level of care for a variety of clinical reasons; however, prescribing patterns of some psychotropic medications have raised concerns regarding the appropriateness of therapy [1-6]. Some studies have shown negative effects of inadequate nurse staffing ratios on quality of care as well as an increase in malpractice paid losses in facilities with lower registered nurse (RN) ratios [7-9]. More specifically related to antipsychotics (APs), a study of 590 patients in Austria, United Kingdom, and Norway found that Norwegian homes with higher staff-resident ratios had relatively less resident agitation and a decrease in the use of APs; however, the authors acknowledged the small sample size of their study as a limitation [10]. Evidence also suggests that many $\mathrm{NH}$ patients on long-term AP regimens do well after reducing and discontinuing the AP, supporting claims that AP use may be influenced by more factors than clinical necessity [11]. The NH industry faces many organizational and operational challenges including nursing staff turnover, high staff position vacancy rates, and nursing 
skill mix adequate for the acuity of admissions [12-14]. This article is based on previously conducted studies and does not involve any new studies of human or animal subjects performed by any of the authors.

\section{Antipsychotics in Nursing Homes}

After the introduction of newer atypical AP medications, clinicians are using psychotropic medications in a larger more diverse population [15]. Evidence associating increased death rates for elderly patients treated for dementia eventually led to a "black box" warning from the Food and Drug Administration [15]. APs are sometimes used in patients with severe cognitive impairment to address challenges with certain behaviors that can be dangerous to both patient and caretaker. Konetzka et al. [16] found that as physical restraint use in $\mathrm{NH}$ residents declined from 1999 to 2008 there was a corresponding increase in AP use in the same population, demonstrating a potential unintended consequence of policies that required public reporting of physical restraints. In 2011, the Office of Inspector General described in a report that $14 \%$ of elderly $\mathrm{NH}$ residents had at least one AP medication, and of the Medicare claims for APs approximately 83\% were for $\mathrm{NH}$ residents with off-label conditions [17]. Another analysis of pharmacy claims data found that $22 \%$ of $\mathrm{NH}$ residents received one or more prescriptions of APs [18].

\section{Staffing Standards}

Nursing Home Reform legislation from the 1987 Omnibus Budget Reconciliation Act (OBRA) has placed staffing standards for NHs certified for Medicare and Medicaid. NHs are federally required to be staffed by a licensed nurse $24 \mathrm{~h}$ per day, 7 days per week, and that at least $8 \mathrm{~h}$ be from an RN. Beyond this federal legislation, some states have implemented additional staffing level requirements for NHs [19]. Park and Stearns [20] found that increasing minimum staffing standards had the potential to increase staffing levels in facilities currently below the standard and also found an association in the reduction of restraint use as staffing was increased. An analysis of 17,552 unique facilities from 1999 to 2004 found that higher direct care staffing requirements did increase total staffing levels in NHs, but changes in nursing skill mix could be influenced by proportion of Medicaid patients in the facility [21]. Staffing level standards are set as a minimum recommendation, but patient acuity mix may also impact the staffing truly required to provide appropriate care [19].

\section{Appropriate Use}

Antipsychotic medication use has garnered much attention with the debate of appropriate versus inappropriate prescribing of these medications to patients within NHs. In 2006, despite black box warnings, most AP use in $\mathrm{NH}$ was for patients lacking an approved indication while only approximately $21 \%$ of adult patients prescribed APs had diagnoses of schizophrenia or bipolar disorder [15]. In a study of long-stay Medicare NH residents in 2007, 31.5\% received at least one AP drug [22]. While this seems high, the investigators reported that $95.8 \%$ of the patients on AP drugs had at least one indication for appropriate use according to the previous Centers for Medicare and Medicaid Services Unnecessary Medication Guidance [22]. Another study of 155,095 residents in the $2004 \mathrm{NH}$ minimum data set (MDS) found that only $48 \%$ of $\mathrm{NH}$ residents prescribed APs were 
considered "appropriate" based on NH quality guidance [23]. Defining appropriate use and the methods of determining the prevalence of appropriate versus inappropriate use remains a controversy, and more studies are needed to address this variable as we consider the impact of NH staffing.

\section{STAFFING LEVELS AND ANTIPSYCHOTIC UTILIZATION}

Studies have demonstrated, directly and indirectly, an inverse relationship between staffing levels and AP use [24-30, 32, 35]. In other words, as staffing levels decrease AP drug use increases. For example, Svarstad et al. [28] observed reductions in AP drug usage after passage of OBRA-87 legislation. In their study, AP reduction was greatest in $\mathrm{NHs}$ with high nurse-resident ratios [28]. Shorr et al. [32] found from their longitudinal study that NHs with higher third shift staffing ratios were more likely to decrease AP use [32]. Schmidt et al. [35] in Sweden found that while staffing did not influence initiation or documentation criteria of AP use, NHs with lower levels of staffing were significantly more likely to have excessive AP use based on their quality measure.

Multiple studies have failed to observe a significant difference between nurse staffing hours and AP drug use [25, 31, 34]. Two of these studies were from Pekkarinen et al. [25, 34] using data from NHs in Sweden. In the 2006 publication, the researchers found an association between high levels of staff job demands and physical restraint use, but not with AP drugs as chemical restraints [25]. In the 2008 publication, Pekkarinen et al. [34] did not find that staffing level was associated with the stated quality measures of pressure ulcer and AP prevalence. However, in this same study, the perception reported from the nurse survey instrument of poor working conditions was associated with AP and pressure ulcers. NHs whose staff reported high levels of "time pressure" and "unfair management" had a higher prevalence of APs [34]. The third study from Lee et al. [31] found that higher $\mathrm{RN}$ staffing hours were associated with fewer pressure ulcers, but that $\mathrm{RN}$ staffing hours were not related to other quality measures (including AP use without an indication).

Fossey et al. [24] found through a randomized controlled trial of $\mathrm{NH}$ residents in England that a staff training intervention focusing on alternatives to drugs for agitation led to a $19.1 \%$ reduction in neuroleptic prescribing. The intervention included a "whole home" approach that addressed factors such as environment, care, and attitude [24]. Kleijer et al. [33] found that NH facilities with the highest prevalence of AP use were more often large facilities in urban communities. Schmidt and Svarstad [36] found during their secondary analysis of a previous randomized controlled trial in Sweden that perceived nurse-physician communication quality was a significant predictor of inappropriate drug use.

\section{MEASURING STAFFING LEVELS}

The primary source of nurse staffing data is typically from government required annual $\mathrm{NH}$ surveys. In the United States, this data is compiled within the online survey certification and automated record (OSCAR). AP drug use and other quality measures were found from pharmacy claims data, components from the MDS, or survey/questionnaires provided by the researchers. However, the Affordable Care Act (ACA) provisions requiring Medicare and/or Medicaid certified NH facilities 
to submit staffing information to be published on a public website may impact how researchers are able to assess the different variables [37]. Capturing details within $\mathrm{NH}$ work environments requires more extensive research, but concepts such as "perceptions of teamwork, mutual respect, and open communication" may be critical to understanding operational effectiveness of a facility [38].

Current evidence of correlation between $\mathrm{NH}$ staffing and AP drug use warrants more rigorous investigation to demonstrate potential causality. Practitioners caring for geriatric patients face many administrative challenges, and testimonial evidence from experienced practitioners describes situations where care has been jeopardized due to workload. The relationship between these two variables would suggest less nurse staffing could increase AP prescribing for $\mathrm{NH}$ residents [24-30, 32, 35]. There also appears to be no consistent evidence of a relationship between the nurse skill mix (i.e., RN, licensed practical nurse, certified nursing assistant) and AP prevalence.

One of the main challenges to studying AP utilization as a variable is determining appropriate versus inappropriate use. The desired outcome with a complex geriatric patient within a skilled nursing facility may be different for each stakeholder involved in the care of that individual. It would be incorrect to imply that any AP use is bad. The existence of an inverse relationship does not guarantee inappropriate use as other factors may impact prescriber decisions to use APs. When comparing staffing level data, considering effectiveness as it relates to outcomes may enable patients and policymakers to make more informed decisions [39].

Further studies are needed to assess staffing variables and AP prevalence in NHs. Studies related to the total number of staffing hours may be valuable but only tell part of the story. In addition to overall staffing hours compared to number of residents, additional factors should be considered. Turnover rates, nurse skill mix, and patient acuity could influence the time nurses have to care for each resident. Higher turnover rates would imply more time needed for training newer nurses. Different nursing skill levels and different levels of resident care demand could have a qualitative impact beyond a quantitative nurse-to-resident measure. Fossey et al. [24] focused on a staff training intervention, while Schmidt and Svarstad [36] investigated nurse-physician communication. In one study that did not observe a statistically significant relationship between staffing hours and AP use, the investigators found that the reported working conditions did impact AP prevalence to further support the need for qualitative measurement [34].

\section{POLICY MOVING FORWARD}

Minimum staffing requirements for $\mathrm{NH}$ facilities can have an impact on total direct care staffing levels [20]. These standards can be set at various levels of government or by payers for NH services. While staffing strategies may be an approach to address AP utilization and quality of care, other levels have demonstrated an impact in this population. Bowblis et al. [40] found that deficiency citation rates for NHs during a prior state inspection have an impact on AP use in response to the citation. Another analysis of the public reporting of AP use demonstrated a decline in use once the facility was subjected to reporting [41]. The ACA's NH quality provisions emphasize transparency through public reporting of staffing and 
expenses [42]. The legislation further addresses $\mathrm{NH}$ workforce issues by including training for certified nurse assistants on dementia, a national program of criminal background checks, and other incentives to grow the supply of more competent workers in this field [42]. The effects of these different approaches on AP utilization provide policymakers with the ability to multiple methods in areas with high levels of inappropriate prescribing.

\section{CONCLUSIONS}

The increased reporting of staffing data mandated by ACA could help researchers explore clinical skill mix; however, controversy exists around the accuracy of this self-reported data, specifically regarding the reported RN staffing hours [37]. Current evidence suggests the existence of a relationship between $\mathrm{NH}$ nurse staffing levels and the prevalence of AP medication use. Although the two variables may appear to be related, more rigorous studies are needed to identify cause and effect while controlling for other possible factors that could influence AP use.

\section{ACKNOWLEDGMENTS}

No funding or sponsorship was received for this study or publication of this article. The named author meets the International Committee of Medical Journal Editors (ICMJE) criteria for authorship for this manuscript, takes responsibility for the integrity of the work as a whole, and has given final approval for the version to be published.

Conflict of interest. T Joseph Mattingly has nothing to disclose.
Compliance with ethics guidelines. This article is based on previously conducted studies and does not involve any new studies of human or animal subjects performed by any of the authors.

Open Access. This article is distributed under the terms of the Creative Commons Attribution-NonCommercial 4.0 International License (http://creativecommons.org/licenses/ by-nc/4.0/), which permits any noncommercial use, distribution, and reproduction in any medium, provided you give appropriate credit to the original author(s) and the source, provide a link to the Creative Commons license, and indicate if changes were made.

\section{REFERENCES}

1. Stevenson DG, Decker SL, Dwyer LL, et al. Antipsychotic and benzodiazepine use among nursing home residents: findings from the 2004 National Nursing Home Survey. Am J Geriatr Psychiatry. 2010;18(12):1078-92.

2. Jung HY, Meucci M, Unruh MA, et al. Antipsychotic use in nursing home residents admitted with hip fracture. J Am Geriatr Soc. 2013;61(1):101-6.

3. Rhee Y, Csernansky JG, Emanuel LL, et al. Psychotropic medication burden and factors associated with antipsychotic use: an analysis of a population-based sample of community-dwelling older persons with dementia. J Am Geriatr Soc. 2011;59(11):2100-7.

4. Ray WA, Federspiel CF, Schaffner W. A study of antipsychotic drug use in nursing homes: epidemiologic evidence suggesting misuse. Am J Public Health. 1980;70(5):7.

5. Alanen HM, Finne-Soveri H, Noro A, Leinonen E. Use of antipsychotic medications among elderly residents in long-term institutional care: a three-year follow-up. Int $\mathrm{J}$ Geriatr Psychiatry. 2006;21(3):288-95.

6. Bronskill SE, Anderson GM, Sykora K, et al. Neuroleptic drug therapy in older adults newly admitted to nursing homes: incidence, dose, and specialist contact. J Am Geriatr Soc. 2004;52:7. 
7. Collier E, Harrington C. Staffing characteristics, turnover rates, and quality of resident care in nursing facilities. Res Gerontol Nurs. 2008;1(3):157-70.

8. Zhao M, Haley DR. Nursing home quality, staffing, and malpractice paid-losses. J Health Care Finance. 2011;38(1):10.

9. Shin JH. Relationship between nursing staffing and quality of life in nursing homes. Contemp Nurse. 2013;44(2):11.

10. Testad I, Auer S, Mittelman M, et al. Nursing home structure and association with agitation and use of psychotropic drugs in nursing home residents in three countries: Norway, Austria and England. Int J Geriatr Psychiatry. 2010;25(7):725-31.

11. Ruths S, Straand J, Nygaard HA, Aarsland D. Stopping antipsychotic drug therapy in demented nursing home patients: a randomized, placebo-controlled study-the Bergen District Nursing Home Study (BEDNURS). Int J Geriatr Psychiatry. 2008;23(9):889-95.

12. Cohen-Mansfield J. Turnover among nursing home staff. Nurs Manage. 1997;1997:4.

13. Maas ML, Specht JP, Buckwalter KC, et al. Nursing home staffing and training recommendations for promoting older adults' quality of care and life: part 1. Deficits in the quality of care due to understaffing and undertraining. Res Gerontol Nurs. 2008;1(2):11.

14. Maas ML, Specht JP, Buckwalter KC, Gittler J, Bechen K. Nursing home staffing and training recommendations for promoting older adults' quality of care and life: part 2. Increasing nurse staffing and training. Res Gerontol Nurs. 2008;1(2):19.

15. Crystal S, Olfson M, Huang C, Pincus H, Gerhard T. Broadened use of atypical antipsychotics: safety, effectiveness, and policy challenges. Health Aff. 2009;28:w770-81.

16. Konetzka RT, Brauner DJ, Shega J, Werner RM. The effects of public reporting on physical restraints and antipsychotic use in nursing home residents with severe cognitive impairment. J Am Geriatr Soc. 2014;62(3):454-61.

17. OIG. Medicare atypical antipsychotic drug claims for elderly nursing home residents. Washington DC: The Office of the Inspector General for the Department of Health and Human Services; 2011 (OEI-07-08-00150).

18. Briesacher BA, Tjia J, Field T, Peterson D, Gurwitz JH. Antipsychotic use among nursing home residents. JAMA. 2013;309:440-2.
19. Mueller C, Arling G, Kane R, et al. Nursing home standards: their relationship to nurse staffing levels. Gerontologist. 2006;46:74-80.

20. Park J, Stearns SC. Effects of state minimum staffing standards on nursing home staffing and quality of care. Health Serv Res. 2009;44:56-78.

21. Bowblis JR. Staffing ratios and quality: an analysis of minimum direct care staffing requirements for nursing homes. Health Serv Res. 2011;46:1495-516.

22. Simoni-Wastila L, Wei Y, Luong M, et al. Quality of psychopharmacological medication use in nursing home residents. Res Social Adm Pharm. 2014;10:494-507.

23. Lucas JA, Chakravarty S, Bowblis JR, Gerhard T, Kalay E, Paek EK, Crystal S. Antipsychotic medication use in nursing homes: a proposed measure of quality. Int $\mathrm{J}$ Geriatr Psychiatry. 2014;29:1049-61.

24. Fossey J, Ballard C, Juszczak E, et al. Effect of enhanced psychosocial care on antipsychotic use in nursing home residents with severe dementia: cluster randomised trial. BMJ. 2006;332(7544):756-8.

25. Pekkarinen L, Elovainio M, Sinervo T, Finne-Soveri $\mathrm{H}$, Noro A. Nursing working conditions in relation to restraint practices in long-term care units. Med Care. 2006;44:1114-20.

26. Kim H, Whall AL. Factors associated with psychotropic drug usage among nursing home residents with dementia. Nurs Res. 2006;55(4):252-8.

27. Hughes CM, Lapane KL, Mor V. Influence of facility characteristics on use of antipsychotic medications in nursing homes. Med Care. 2000;38(12):1164-73.

28. Svarstad BL, Mount JK, Bigelow W. Variations in the treatment culture of nursing homes and responses to regulations to reduce drug use. Psychiatr Serv. 2001;52(5):666-72.

29. Miller SC, Papandonatos G, Fennell M, Mor V. Facility and county effects on racial differences in nursing home quality indicators. Soc Sci Med. 2006;63(12):3046-59.

30. Castle NG, Engberg J. An examination of special focus facility nursing homes. Gerontologist. 2010;50(3):400-7.

31. Lee HY, Blegen MA, Harrington C. The effects of RN staffing hours on nursing home quality: a two-stage model. Int J Nurs Stud. 2014;51(3):409-17.

32. Shorr RI, Fought RL, Ray WA. Changes in antipsychotic drug use in nursing homes during 
implementation of the OBRA-87 regulations. JAMA. 1994;271(5):358-62.

33. Kleijer BC, van Marum RJ, Frijters DH, et al. Variability between nursing homes in prevalence of antipsychotic use in patients with dementia. Int Psychogeriatr. 2014;26(3):363-71.

34. Pekkarinen L, Sinervo T, Elovainio M, Noro A, Finne-Soveri H. Drug use and pressure ulcers in long-term care units: do nurse time pressure and unfair management increase the prevalence? J Clin Nurs. 2008;17(22):3067-73.

35. Schmidt I, Claesson CB, Westerholm B, Svarstad BL. Resident characteristics and organizational factors influencing the quality of drug use in Swedish nursing homes. Soc Sci Med. 1998;47(7):961-71.

36. Schmidt IK, Svarstad BL. Nurse-physician communication and quality of drug use in Swedish nursing homes. Soc Sci Med. 2002;54(12):1767-77.

37. Turner SA. Update on nurse staffing obligations in skilled nursing facilities. Geriatr Nurs. 2015;36:59-60.
38. Dellefied ME, Castle NG, McGilton KS, Spilsbury K. The relationship between registered nurses and nursing home quality: an integrative review (2008-2014). Nurs Econ. 2015;33(2):95-116.

39. Kirby KK. Hours per patient day: not the problem, nor the solution. Nurs Econ. 2015;33(1):64-6.

40. Bowblis JR, Crystal S, Intrator O, Lucas JA. Response to regulatory stringency: the case of antipsychotic medication use in nursing homes. Health Econ. 2012;21:977-93.

41. Bowblis JR, Lucas JA, Brunt CS. The effects of antipsychotic quality reporting on antipsychotic and psychoactive medication use. Health Serv Res. 2015;50:1069-87.

42. Miller EA, Nadash P. The affordable care act and long-term care: marginal advancement on the status quo. Home Health Care Serv Q. 2014;33:194-210. 